\title{
Anxiety during pregnancy among Sudanese pregnant women
}

\section{Abstract:}

Shafeig Hussein, MD*

Many women suffer psychological symptoms during pregnancy but few studies have examined anxiety among pregnant ladies in relation to the level of education, previous bad obstetrical history and female circumcision.

Aims: To determine frequency of anxiety among Sudanese women as related to pregnancy and customs related factors.

Methods: 50 pregnant ladies and 50 matched controls were studied at the antenatal clinics of three major hospitals in Khartoum utilizing the Taylor Manifest Anxiety Scale. Data was fed to SPSS and significance was taken at P 0.05 .

Results: Three of the variables in the study were independently associated with anxiety during pregnancy. These were previous still birth $(P 0.0370)$, female genital mutilation (pharaonic circumcision) $(P 0.0070)$ and the low level of education $(P 0.004)$.

Key words: pregnancy, anxiety.

Anxiety disorders are abnormal states associated with physical and mental symptoms and are not due to organic brain disease or other psychiatric disorders. Anxiety is associated with somatic complains during pregnancy ${ }^{1,2}$. The first trimester is characterized by considerable emotional liability and irritability with an underlying anxiety state. There are characteristic changes in appetite, with tendency for food that women do not usually consume. The psychological factors are the cause of initiation of nausea and vomiting which are commonly experienced. The second trimester is usually associated with increased self-confidence, the earlier nausea subsides and the lady becomes more concerned with herself and her baby's details. The last trimester is characterized by lethargy, both physical and emotional. In the last few weeks of pregnancy fears for personal safety and baby's wellbeing appear. Fears may be due to the friends, old wives' tales and previous unhappy experience.

We studied the personality changes of pregnant ladies to find out the impact of previous still birth, level of education and pharaonic circumcision.

\section{Patients and methods:}

This is a case control study in which 50 pregnant ladies and 50 matched non-pregnant controls were studied. The psychological assessment took place in the antenatal clinics of Khartoum Teaching Hospital, Khartoum North Teaching Hospital and Omdurman Maternity Hospital from April 2002 through Nov 2002.

\footnotetext{
* Assistant Prof. Department of Psychiatry, Omdurman Islamic University. Correspondence to: Shafeig2000@yahoo.com
}

All participants were interviewed by the author using the Taylor Manifest Scale ${ }^{3}$ which is a true and false instrument referable to physical and emotional aspects of anxiety. Pregnancy related anxiety was measured using a modified questionnaire from the previous work by Leaderman ${ }^{4}$.

\section{Exclusion criteria:}

All pregnant women with medical illnesses that may interfere with the cognitive function, patient suffering from psychosis and patients who have poor Arabic or English language were excluded.

Analysis:

Data was fed to Statistical Package for Social Sciences (SPSS). $\mathrm{X}^{2}$ was use to find out the association of the variables in the study with anxiety. Significance was taken at P 0.05.

\section{Results:}

The mean $( \pm \mathrm{SD})$ age was $27( \pm 9)$ and range 16- 37 years (Fig 1).

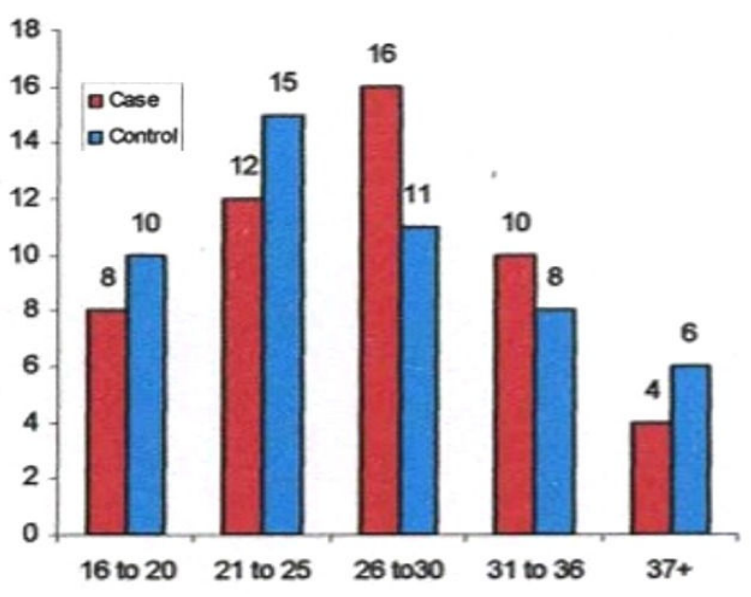

Fig1: Distribution of case and control by age groups 
Patients and control group are similar in parity as shown in Fig 2

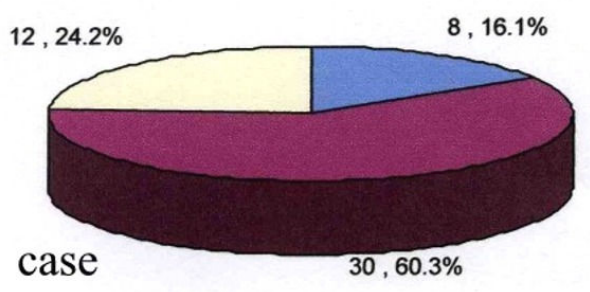

口 primipara

a multipara

$\square$ grandmultipara

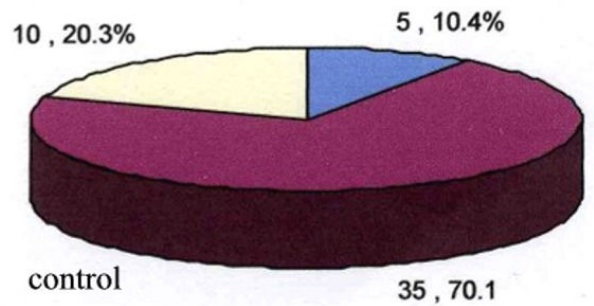

Fig 2. Cases and control group based on parity

Patients in the study were generally less educated than the control group as depicted in Fig $3\left(\chi^{2} 9.11, P 0.004\right)$.

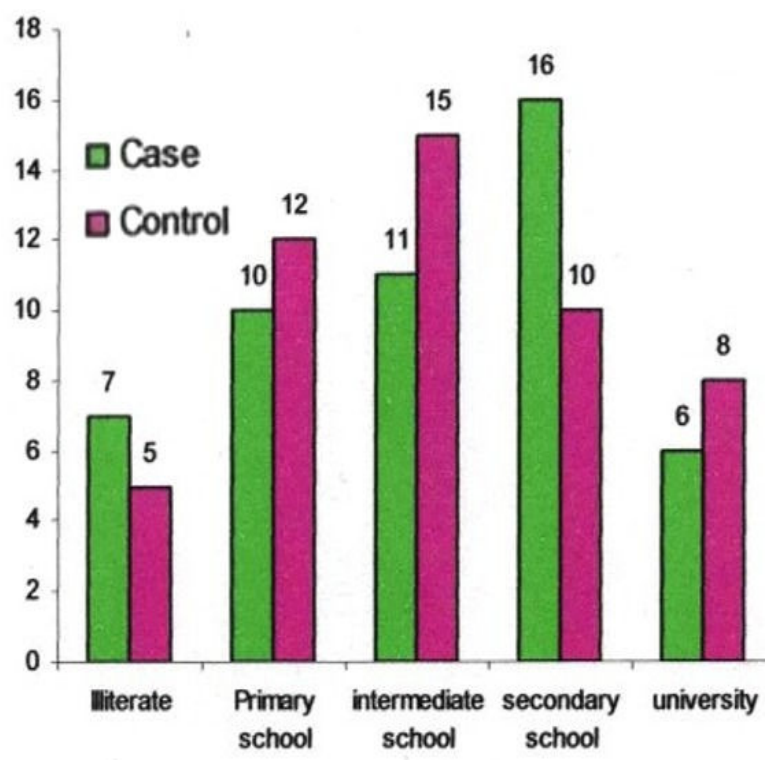

Fig 3. cases and control by education level.

Anxiety increases with time in the studied group being $30.1 \%$ in first trimester, $10.7 \%$ in second trimester and 60\% in third trimester in contrast to the control group as seen in Fig 4.

Serious maternal disharmony was found in $58 \%$ of the studied group and $24.9 \%$ of the controls. In this study the negative impact of poor husband-wife relationship to pregnancy was clearly evidenced in individual cases in which separation had already taken place and commitment was uncertain for one or both partners.

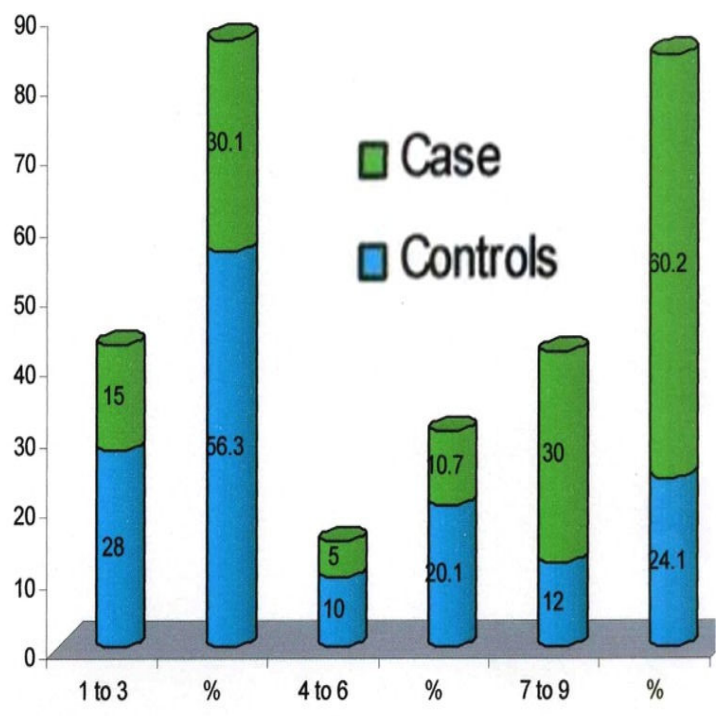

Fig 4. Variation of anxiety during pregnancy with duration of pregnancy.

There was no significant difference with regard to the presence of poor socio-economic status and anxiety during pregnancy ( $\mathrm{P}$ 0.275). Stressful circumstances ranged from financial anxiety and dissatisfaction of the husband job.

In the studied group $72.2 \%$ were suffering from anxiety related to delivery complications compared to $36.4 \%$ in the control group ( $P$ $0.0004)$. Anxiety was particularly common in women who had more than one stillbirth. This occurred in $84.9 \%$ of the studied group in comparison to $66.3 \%$ of the control group ( $P$ 0.037).

There is statistically significant relation between anxiety and female Pharaonic circumcision in $78.7 \%$ of the studied group as compared to $38.3 \%$ of the control group ( $P$ 0.0070). 


\section{Discussion:}

Anxiety is a painful reaction to an internal conflict. Both anxiety and fear activate complex physiological mechanisms that prepare the person for fight and flight response. Sudan is a developing country where traditions still call for a large family. Girls marry at an early age and continue to have children to the end of their reproductive life. Our results were consistent with others particularly in the high risk group ${ }^{5}$ i.e. those younger than 20 and older than 37 years. Our finding that the less educated ladies suffer more from anxiety is in keeping with reports in the literature ${ }^{6,7}$. Also, our findings that anxiety is more in the last 2 months of pregnancy are consistent with others' findings ${ }^{8}$. The worry of pregnant ladies to give birth of an abnormal baby increases more if she had personal or family history of abnormal babies? .

In Sudan, although females participate in the per-capita incomes, males are generally considered as the main breadwinners. Yet, in this study there was no significant effect of the socioeconomic status on the frequency of anxiety in pregnancy. This could be explained by the fact that people of this country are strong believers on God's will. This observation is rather different from the other researshes ${ }^{10}$. However, the effect of the sex of the forthcoming baby on paternal behavior has received more attention in the literature $^{11}$. In this study the anxiety among pregnant ladies who prefer to bear male infant was $70.2 \%$ compared to those on the control group $40.1 \%$.

Fear of delivery and fear of labor pains represent a major cause of anxiety. Nonetheless, the popularity of female circumcision in this society increases the anxiety because of fear of difficulty, tear or pain during dilivery ${ }^{12}$.

As in the literature ${ }^{2,13-15}$, in this study we found that past history of still birth leads to more worry, irritability, fear, and restlessness as psychological impact of previous still birth.

\section{Conclusion:}

Previous still birth, Pharaonic circumcision and poor educational level are significant risk factors for anxiety during pregnancy. Therefore, we do recommend that doctors, midwives and health visitors should be well trained to look after psychological aspects of pregnant ladies to relief anxiety and build self-confidence.

\section{References:}

1- Gorsuch RL, Key MK. Abnormalities of pregnancy a function of anxiety and life stress. Psychosom Med 1974; 36: 352.

2- Barabra L. Psychological Aspects of pregnancy. Am J Obstit Gyecol 1980; 113: 598

3- Taylor JA. A Personality Scale of Manifest-Anxiety. J Abnormal and Social Psychology. 1953; 48: 285-295.

4- Lederman RP. Maternal anxiety in pregnancy: relationship to fetal and newborn health status. Annu Rev Nurs Res. 1986; 4: 3-

5- Omran AR. The Health Theme in Family Planning. Chapel Population Centre. Monograpgic series, No. 16.

6- Burstein I, Kinch RA, Stern L. Anxiety, pregnancy, labor and the neonate. Am J Obstit Gynecol. 1984; 118: 195.

7- Lightfoot EC, Keeling B, Wilton K. Characteristics distinguishing- high - anxious and medium, low anxious women during pregnancy. J Psychosom Research. 1982; 26: 343-352.

8- Grimm ER. Psychological tension in Pregnancy. Psychosom Med. 1961; 23: 520527.

9- Jessner L. Pregnancy as stress in marriage. Marriage Counseling in Medical Practice.

10- Rapoport R. Normal Grises, family Structure and Mental health. Process 1973; 2: 68-80.

11- Rothbart MK. Maccoby EE. Patients Differential reactions to sons and daughters. J Personality and Social Psycology 1966; 4: 237-243.

12- El Darrer A. Circumcision and its consequences. Women why do you weep. London $2^{\text {nd }}$. ed 1982, p 470-472.

13- Hughes $\mathrm{P}$, Turton $\mathrm{P}$ and Evans $\mathrm{CDH}$. Stillbirth as a risk factor for anxiety and depression in the next pregnancy: does time 
since loss make a difference? BMJ. 1999; 318: 1721-1724.

14- Friedman E and Gath B. The consequences of spontaneous abortion. BJP 1989; 155: 810-813.
15- Turton P P, Hughes P, Evans C D. The incidence and significance of post-traumatic stress disorders in the pregnancy after stillbirth. BJP 2001; 178: 556-560. 